\title{
Range of technical-economic competitiveness of rail-road combined transport
}

\author{
Angela Carboni* ${ }^{*}$ and Bruno Dalla Chiara
}

\begin{abstract}
Purpose: Road haulage has been the most widely used mode of freight transport in many European countries for several decades. Given the attention to sustainable transport in this century, the rail-road combined transport may result to be a good alternative, under specific conditions, to road haulage. This paper analyses the main conditions to make the option competitive, using a simplified method useful for the stakeholders involved in decision processes.

Method: Relevant cost items have been identified since previous studies available in literature. The proposed formulas consider the different phases of transport chain and have been used to investigate such parameters as the external costs and the location of terminals.

Results: If the pre- and post-phases are too long or simply too onerous, the economic advantages of the rail section may not be sufficient to guarantee the convenience of the combined transport. It can be economically competitive over long distances, even when the drayage covers greater distances.

Conclusions: The method has been used to examine those situations, in terms of distance covered and frequency of the service, in which rail-road combined transport can be cost-effective as an alternative to the full-road solution. The obtained range can be reviewed based on the services, such as shuttle trains to connect seaports with dry ports: the short distance covered may be more convenient due to the high quantities of goods as well as the fixed train composition and path allocation, which means lower terminal cost and times. Finally, some innovative proposals have been introduced.
\end{abstract}

Keywords: Freight transport, Rail-road combined transport, Internal costs, Externalities

\section{Introduction and state of the art}

The European White Paper on transport 2011 [1] envisages that freight transport is likely to continue being mainly carried by trucks over short and medium distances (roughly, below $300 \mathrm{~km}$ ). The options for road transport over longer distances are more limited, and freight multimodality should become economically attractive for shippers and forwarders. According to some aims outlined in [1], 30\% of road freight over $300 \mathrm{~km}$, such as rail or waterborne transport, should be shifted to other modes of transport by 2030; this value is expected to rise to more than $50 \%$ by 2050 , also as a result of the introduction of efficient green freight corridors.

\footnotetext{
* Correspondence: angela.carboni@polito.it

Politecnico di Torino, Engineering, Department. DIATI - Transport systems, 24, Duca degli Abruzzi, 10129 Torino, Italy
}

Intermodal transport might be a good solution to accomplish these White Paper recommendations, since rail transport, in most cases, does not allow door-todoor transport. According to the Economic European Commission, intermodal transport is "the movement of goods in one and the same loading unit or road vehicle, which successively uses two or more modes of transport, without handling the goods themselves in changing modes" [2]. In addition, intermodal transport can be defined as combined transport, according to the definition outlined in Directive 92/106/CEE: "a transport between EU Member States where the lorry, the trailer or semi-trailer with or without motor coach, the swap body or the container cover the initial or final part of the travel, as short as possible, by road while the prevailing intermediate one by railway, sea or inland waterways". 
The following conditions have conventionally been considered in the last few decades for funding reasons, although they now seem to have been exceeded, as shown later on in this paper:

a) the path covered by railway, sea or inland waterways should exceed $100 \mathrm{~km}$, as the crow flies;

b) the initial or final parts of the road journey should include the path between the freight loading point and the nearest suitable loading railway terminal, or the freight unloading point and the nearest suitable unloading railway terminal, otherwise it should be included within a radius that does not exceed $150 \mathrm{~km}$, as the crow flies, from the loading or unloading inland waterway port or seaport (Directive 92/106/CEE).

In this paper, we will mainly deal with rail-road combined transport or ferroutage, in which the main distance is covered by rail, and the road solution is only adopted for pre- and post-haulage (also called drayage ${ }^{1}$ ). The rail-road transport we refer to is unaccompanied, and the driver therefore does not follow the goods along the path covered by the alternative mode. A modal shift is carried out by using suitable handling equipment in specific nodes of the transport network, i.e. inland terminals (sometimes called freight stations, that is, when depot areas are included), which may or may not be matched with a freight village or a logistics centre [3].

The main goal of this paper is to evaluate the range of technical and economic competitiveness of combined transport, primarily in terms of covered distance, by using a simple method and with the support of realistic data. The simplicity of the method and the related calculations allow a proper dissemination among the actors involved in the decision-making processes (Multimodal Transport Operators or politicians, for instance). In order to achieve the aim, it is important to consider both the well-known range of convenience of different transport modes and the European environmental constraints that mainly affect the road sector. This analysis can widen the area that can be covered by combined transport, including, for example, the port-hinterland connection and the introduction of electric vehicles to cover road terminations for short haulages, thus reducing the operational costs.

In order to investigate the economic attractiveness while also considering environmental aspects, it is useful to consider both the internal and external costs. In this context, the European Commission has also highlighted the need to establish a more efficient transport pricing, in order to better reflect the actual cost of transport. Transport, as is well known, generates negative externalities that can be translated into costs for both society and the economy; the internalisation of external costs can, at least in part, establish or pursue fairer prices [4]. The research on external costs of freight transport has increased in the last few years, due to their increasing impact on the economy, environment, climate and society [5]: this subject will be dealt with later on in the paper. It is also interesting to recall the comparison, in terms of relevance, of the negative externalities between different transport modes, focusing on road and rail transport (see Fig. 1).

The relevant aspects that are addressed within the paper are: the role of rail-road combined transport and its competitiveness, the role of inland terminals and our economic considerations.

The first element was examined by Mathisen and Hanssen [6] through a historical research on intermodal freight transport. Their paper underlined the growth in the number of published articles from 2000 onwards, which can reasonably be attributed to the intense political focus on intermodal freight transport. Islam et al. [7] also began their work by considering the indications of the EU's White Paper 2011 and by analysing a framework to pursue a modal shift from road to rail. They underlined that the rail alternative should provide some implementations to offer a competitive price, such as the operation of heavier and longer trains, wider loading gauges, higher average speeds, and a better utilisation of wagon space. Implementations for improving intermodal freight transport were also studied by Skočibušić et al. [8]. They in particular summarized

\begin{tabular}{|c|c|c|c|c|c|}
\hline Negative externalities & Road transportation & Rail transportation & Maritime transportation & Air transportation & Pipeline transportation \\
\hline Air pollution & *** & ** & ** & ** & * \\
\hline Greenhouse gases & $\star \star \star \star$ & $\star \star \star$ & $\star \star \star$ & $\star \star \star$ & * \\
\hline Noise pollution & $\star * \star$ & ** & ** & ** & * \\
\hline Water pollution & * & * & $\star \star \star *$ & * & * \\
\hline Congestion & $\star \star \star *$ & * & * & * & * \\
\hline Accidents & ** & * & * & * & * \\
\hline Land use & ** & ** & * & * & * \\
\hline *Low $\quad{ }^{\star \star}$ Medium & *** High & & & & \\
\hline
\end{tabular}

Fig. 1 Relevance of the negative externalities per transport mode [5] 
some important aspects of intermodal freight transport, such as the introduction of an ICT solution to improve efficiency, or a distance for competitive combined transport equal to $300 \mathrm{~km}$. These considerations were provided on the basis of a literature review. Frémont and Franc [9] suggested that the transfer to rail-road combined transport could occur if the price of the combined alternative were attractive: according to the involved operators, the price would need to be $10-20 \%$ lower than the road solution.

The complex model proposed by Hanssen et al. [10] is interesting to evaluate the generalized costs of intermodal freight transport. They found that, in order to make intermodal choice competitive, the distance covered by the alternative mode should increase because when the handling costs at terminals increase, the total transport distance increases, the pre- and post-haulage costs increase, the distance-dependent marginal generalized costs for rail increase, the distance-dependent marginal generalized costs for trucks decrease and the resting costs for truck drivers reduce. In our paper, some of these points have also been investigated and similar results have been obtained, but by means of a simpler method. The purpose of intermodal transport development is sustainability, especially from the financial and environmental points of view, therefore intermodal terminals should also be planned and developed according to this perspective. The relative importance of the factors that influence the break-even distance of intermodal freight transport were also analysed by Kim and Wee [11]. Using a Monte Carlo-based model, they evaluated the role of geometric and cost factors, including: drayage distances, rail distances, the shape of market areas, terminal locations, drayage truck rates, terminal handling rates, etc.

The role of intermodal terminals is of fundamental importance for the competitiveness of railroad combined transport. Ballis [12] analysed the role of the quality of services in the design and operation of freight terminals. His goal was to provide a set of standards that would be useful for investment strategies and terminal design. The interesting aspect, from the point of view of our paper, is the typical cost versus volume curve for intermodal terminals. The purpose of Behrends and Flodén [13] was instead to analyse the effects of terminal costs on the network performance of intermodal line-trains. Their results confirmed that, in theory, intermodal transport could provide competitive services over short and medium transport distances when the transhipment costs are kept low. They also studied the effect of lower transhipment costs on the production costs. Their case study was focused on a path that included several terminals without road haulage, and which only had a line-train service. The position of terminals is a strategic issue: Carreira et al. [14] suggested an optimisation model for the location of intermodal terminals in a freight transport system. They in particular analysed how a catchment area around the terminal could increase if the external costs were included in the decision process. Limbourg and Jourquin [15] also evaluated terminal locations in their paper, using an iterative procedure based on the p-hub median problem, which takes into account the variation in trans-shipment costs according to the number of transhipped intermodal transport units. They considered the influence of terminal locations using the pre- and post-haulage costs.

Finally, economic considerations have been dealt with in some papers. Santos et al. [16], for instance, analysed the effect of some transport policies with the aim of promoting rail-road intermodal transport in Europe. One of these policies regards the internalization of the external costs related to the drayage length, which is also an important aspect in our paper. They proposed, through a practical application in Belgium, an innovative mixed integer intermodal freight location-allocation model, based on the hub-location theory, and deal with non-linear transport costs in order to replicate the economies of distance. Mostert and Limbourg [17] presented the state of the art about the external costs of freight transport, while Kos et al. [18] focused their research on the container transport chain. The former work also compared the total costs of road and rail-road combined transport, using Janic's fomulas [19], by varying the drayage length. Their results did not show the trend of the costs related to a single component (drayage, terminals and rail), but only the amount of each. The above-mentioned paper by Janic [19] considered the externalities by means of a model that was proposed to calculate the internal and external costs of intermodal and road freight transport networks. His interesting approach considered a network with several origins and destinations that converged in two main terminals. The author found significant results using some assumptions and detailed formula and considering the time components. His paper was focused on the door-to-door distance, but the influence of the drayage length did not emerge. Janic found that the full costs decrease more than proportionally as the door-to-door distance increases, thus suggesting economies of scale.

This paper starts with a theoretical description of the main characteristics of intermodal and combined transport (section $\$ 2$ ). The section is made up of three subsections: a review of the relevant elements related to the internal and external costs, a simplified method to assess the total costs of rail-road transport and then different scenarios are presented. The results are discussed in section $\$ 3$. Section $\$ 4$ presents some technical evaluations that are used to further explore the range of competitive distances for rail and combined transport. The starting point of this paper was a previous one by Dalla Chiara \& 
Pellicelli (2011), which suggested the basis for a combined transport cost evaluation.

\section{Rail-road combined transport costs \\ 2.1 Internal costs}

The operations of a rail-road combined transport chain $^{2}$ usually involve the following main costs [19-21]:

- initial road haulage (pre- haulage), with the related organisational costs, which are generally provided by road transport companies. These costs include the ownership and the use of vehicles, the use of the infrastructure (taxes, toll) and the costs generated by the down-time time during the loading and unloading operations;

- operations in the starting terminal;

- haulage through the railway connection, the costs of which are linked to the mode itself and to the use of the infrastructure;

- operations in the arrival terminal;

- final road haulage and the related organisational costs, such as pre- haulage;

- cost for the use of the Intermodal Transport Units $\left(\right.$ ITUs $\left.^{3}\right)$;

- cost for the use of railway wagons for the intermodal transport;

- organization and management costs of the railway operator.

The breakdown of the costs into their standard items allows a few common components to be defined:

- depreciation costs of all the instruments and means used along the intermodal transport chain;

- staff costs;

- consumption costs, that is, all of those costs that are required to provide fuel, oil, tyres and the necessary power for all the modes of transport;

- maintenance costs, which include the routine maintenance and repairs of the transport means (lorries/trucks, railway wagons, ships...) and loading units. This item does not include the infrastructures;

- insurance costs;

- taxes, which are paid on the purchase (or rental) and on the use of vehicles and ITUs;

- tolls, which are paid for the use of some infrastructures.

If a general comparison is made between the composition costs of a road and railway vector, some asymmetries emerge. The characteristics of an infrastructure are: slow (along traditional railways, not on high speed ones, however so far rarely used for freight) and rigid for railways, as regards freight, while road transport is frequently faster, in part thanks to the far wider capillarity of the road network and the possibility of avoiding two modal shifts. The latter is also possible by rail, but only when shuttle trains from industry to industry are pursuable, in terms of quantity and availability of track links connected to the main railways (which are usually foreseen by the rail infrastructure manager for heavier traffic than 2-3 trains/week).

Haulage through the railway connection generally presents the lowest unit cost (per $\mathrm{km}$ ), besides specific energy consumption, mainly because of the traffic concentration. On the other hand, the costs of the initial and final road haulage, although not directly dependent on the distance covered, could reach high amounts that may make combined transport vs. the full road choice unaffordable. In fact, road haulers run entrepreneurial activities whose daily costs are not always related to the covered distance but which can depend on the number of services between the terminal and the place of origin or the destination of the goods they perform a day. Moreover, the road congestion of urban and suburban areas where they operate for the "last mile", which is called pre/post haulage or drayage in this paper, could involve considerable additional time (and consequently additional costs). Again, in terms of timing, we should also add the time spent by the truck driver inside the intermodal terminal for the loading and unloading operations (turnaround time).

Other costs that are not distance-related are those concerning the handling operations and the management of ITUs in the starting and arrival terminals. The cost of the intermodal terminal includes depreciation and interest charges, maintenance (land, infrastructure and equipment), staff salaries, operating costs (energy, consumables, and general expenses), miscellaneous expenditure (insurance...) and taxes. It is commonplace to note that, if the terminal cost in the trend of total costs for freight transport affects the final cost to a great extent, the intermodal choice loses its attractiveness (see Fig. 2). Therefore, intermodal services, based on transhipment technologies that make it fast and efficient, can be sufficiently competitive in comparison to all-road medium and long distances.

It is possible to observe, in a typical cost/distance trend, related to combined transport, the influence of the terminal operations (see Fig. 3). These contribute to the final cost, irrespectively of the distance, and of the constant value for final haulages over short distances.

It is not easy to obtain intervals of costs for the different components of the freight transport chain, since 


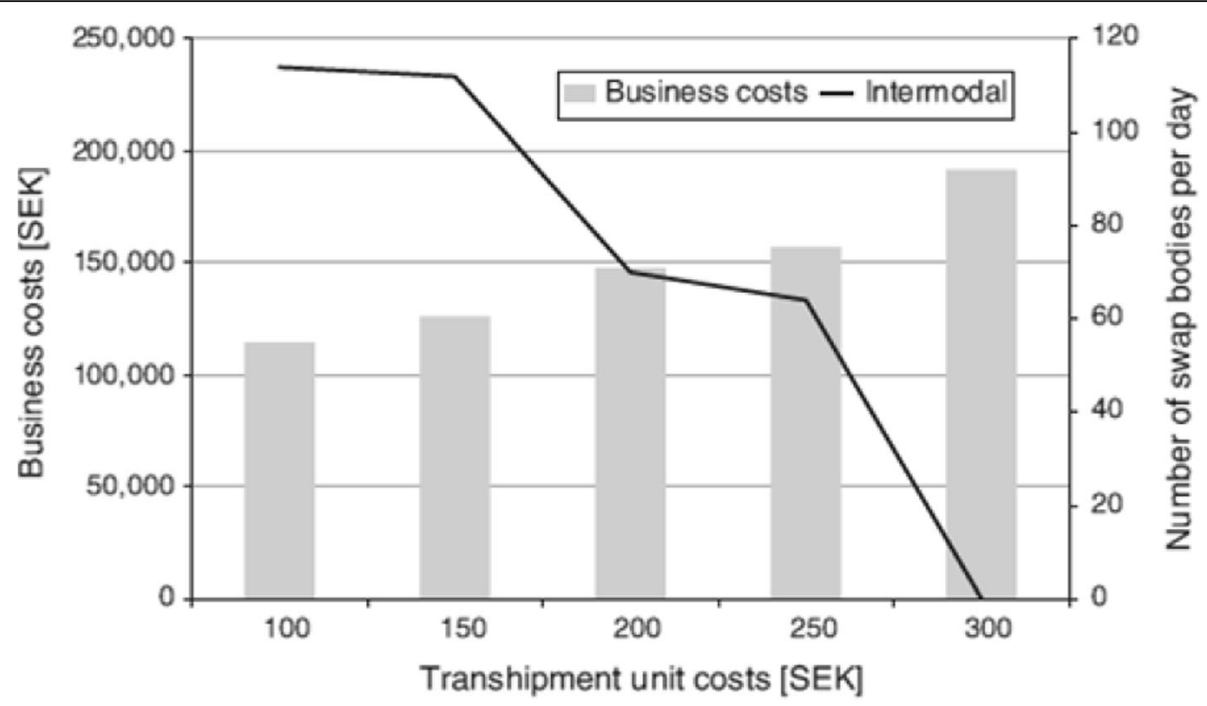

Fig. 2 Total cost trend in SEK, as a function of terminal operations costs [13]

economic and marketplace reasons frequently imply discretion. The RECORDIT Project, REal COst Reduction of Door-to-door Intermodal Transport, supported by a European Commission, defined some internal cost items [21], which were also reported in [11]. The following values are average values of European countries:

- "Road only" cost $\rightarrow 0.58-1.37 € / \mathrm{km}$ for an ITU $\left(40^{\prime}\right)$, with an assumed vehicle utilisation rate of 0.85 ;

- pre- and post-haulage cost $\rightarrow$ the cost is higher than the value for road haulage over long distances; it is in fact $1.23-3.78 € / \mathrm{km}$ for an ITU $\left(40^{\prime}\right)$. This item, as stated above, does not usually depend on the distances, but the range of significant values is used for comparison purposes;

- rail haul cost $\rightarrow$ which is generally lower than the road cost, with an average range of between 0.46 and $1.35 € / \mathrm{km}$;

- terminal cost $\rightarrow$ the gateway movements involve an estimated cost of $27 €$ for an ITU (40'), instead, for the case of road-rail transfer, this amounts to from 36 to $60 € / \mathrm{ITU}$.

\subsection{External costs}

On average, rail-road services result to be four to seven times more energy efficient than trucks: this is a direct consequence of the physical rolling resistance $(\sim 1.5 \div 8 \mathrm{k} / \mathrm{kN}$ for the rolling stock vs. at least $\sim 15 \mathrm{~N} /$

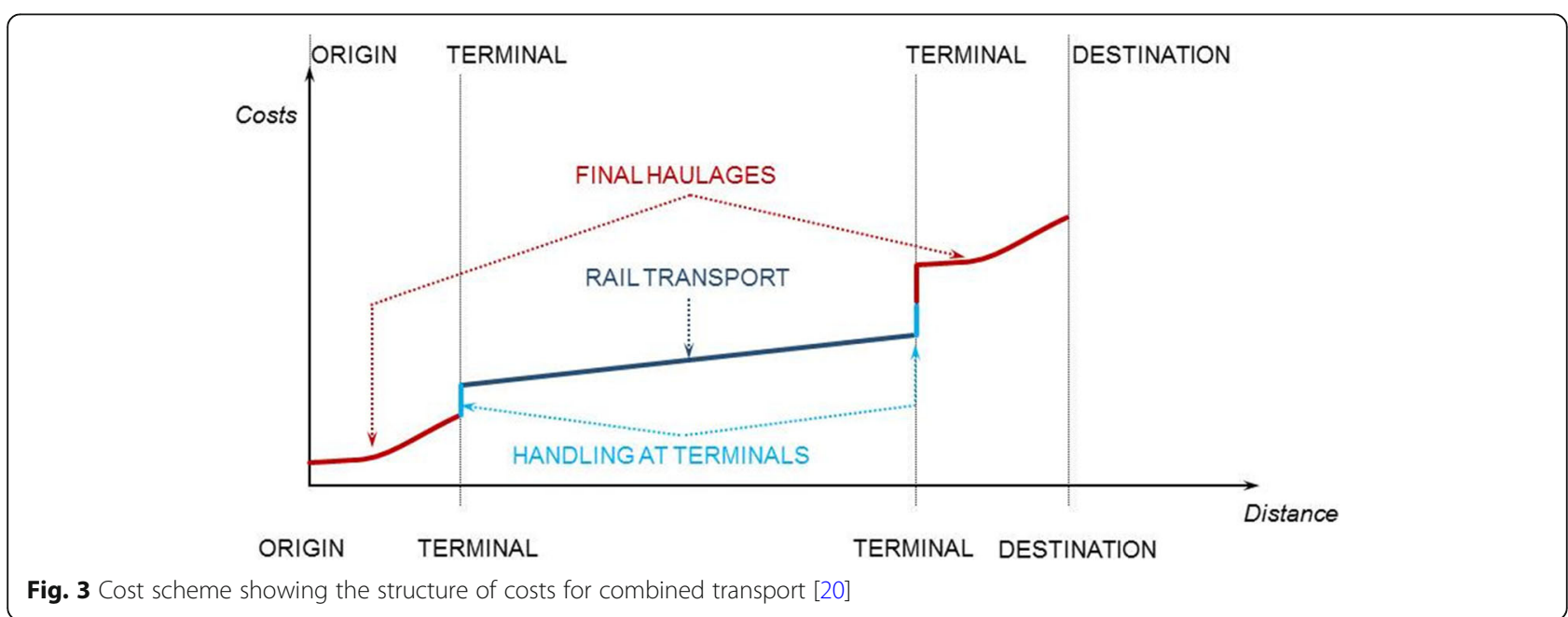


kN for heavy duty vehicles). Subsequently, since greenhouse gas emissions are related to fuel consumption, moving goods by rail can reduce the GHG emissions by as much as $75 \%$, according to [22]. This is especially true if the energy source is used in a different way in the two modes: in the former case, from oil-derived fuels, usually gasoil, while typically through the electric grid and diversified primary sources in the latter one. According to Horn and Nemoto [23], intermodal freight transport in Europe results in 60-80\% fewer accidents and 40-50\% lower $\mathrm{CO}_{2}$ emissions than road transport; the overall social cost saving is $33-72 \%$, compared to road transport, and an external cost saving of 1 Euro for $85 \mathrm{t}-\mathrm{km}$ shifted from road to rail, for $52 \mathrm{t}-\mathrm{km}$ shifted to an inland waterway and for $50 \mathrm{t}-\mathrm{km}$ shifted to coastal shipping. According to our analyses, the consumption and emission trends for the case of rail-road combined transport present a similar structure to that of costs, that is, discontinuous due to the presence of terminals (see Fig. 4).

Therefore, the evident advantages of intermodal transport mainly result to be related to the decrease in external costs. According to [6], with their hypotheses, these result to be just $28 \%$ (per ton- $\mathrm{km}$ ) of the external costs involved in road haulage, and this gap tends to be greater if the calculations include costs due to congestion. In agreement with these results, Santos et al. [16] pointed out that the internalisation of externalities is not always an advantage, especially as far as shipments over short or medium distances are concerned, because pre and post road haulage has a great effect on the price of transport. Some of the negative externalities for freight transport are shown in Fig. 5. Subsequently, we take into account air pollution, noise pollution and greenhouse gases emissions.

\subsection{Cost calculation}

On the basis of the data taken from selected studies shown in sections 1 and 2, linear formulations have been drawn up for a comparison between the costs of road-rail combined transport and full road transport. The results were then processed with the MATLAB tool in order to ensure flexibility and simplicity, in consideration of the analysis of future implementations.

The costs that are described and calculated hereafter refer to two main reference scales, namely: distance and volume (ITUs).

When all the cost items of freight transport from point A to point B were analysed, for the purposes of a simplified but exhaustive calculation for a comparison between the alternative all-road and combined rail- road modes, we referred to the research presented by Dalla Chiara and Pellicelli [20] as a starting point.

Thus, two points, $\mathrm{A}$ and $\mathrm{B}$, were considered to be at a distance of $1500 \mathrm{~km}$. The distance between the origin and the nearest inland terminal was assumed, for

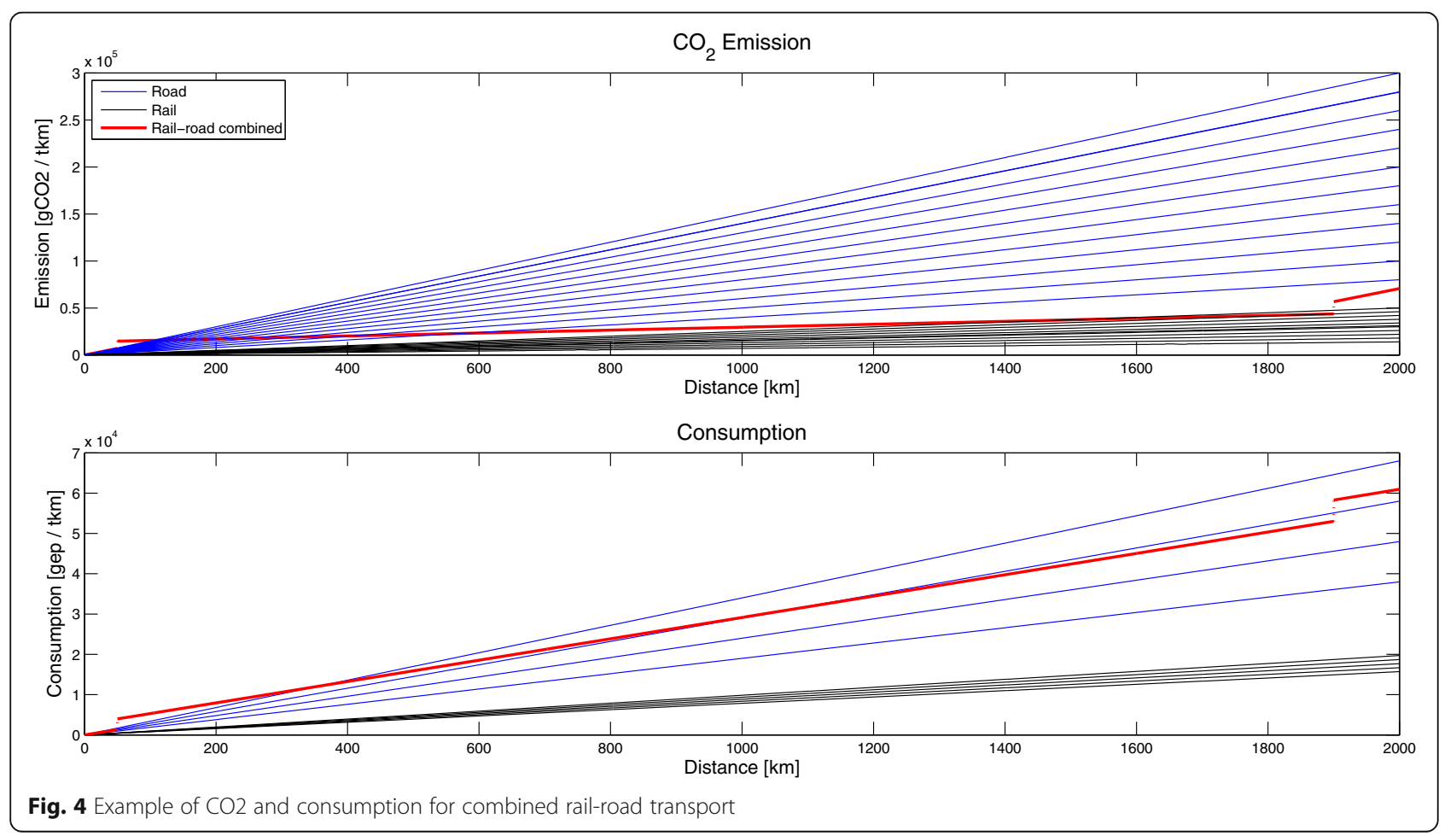




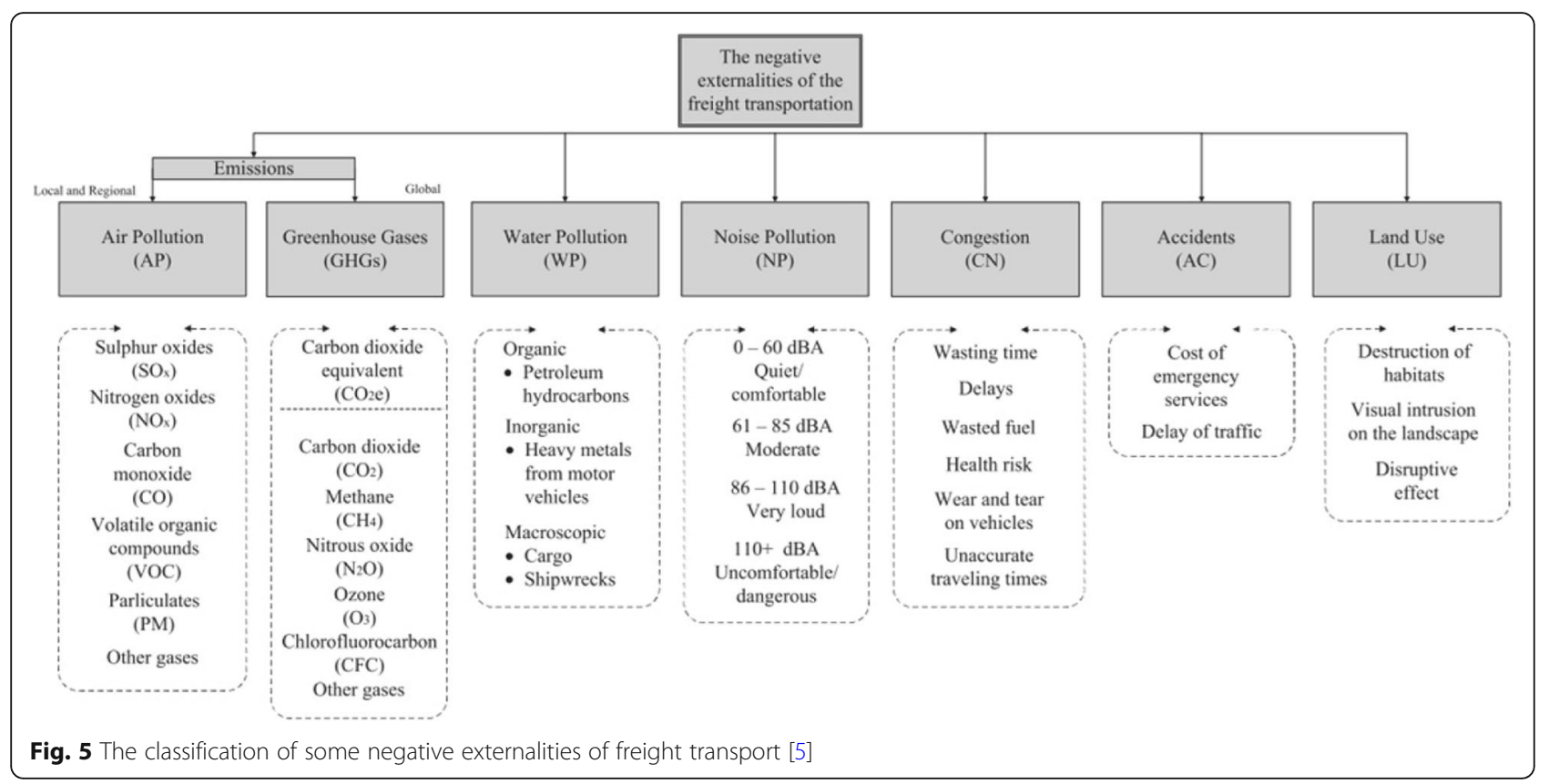

computational reasons, to be the same as that between the second terminal and the destination, whose value was varied in the different scenarios. The distances covered by rail and only by road were considered to be equal, even though this is not always the case; the error became marginal when dealing with long door-to-door distances. The input data, which were obtained from the studies described in the previous sections, were classified as internal and external parameters, as well as being, or

Table 1 Typical internal and external costs for freight transport (ITU 40') (adapted from [21])

\begin{tabular}{|c|c|c|c|}
\hline \multicolumn{2}{|c|}{ Cost item } & \multicolumn{2}{|l|}{ Cost } \\
\hline \multicolumn{4}{|c|}{ Internal costs } \\
\hline Croad & Road & 0,98 & $€ / \mathrm{km}$ \\
\hline$c_{h}$ & Pre/post road haulage & 2,51 & $€ / \mathrm{km}$ \\
\hline $\mathrm{Crl}_{\mathrm{rl}}$ & Rail & 0,91 & $€ / \mathrm{km}$ \\
\hline$c_{t}$ & Terminal operation & 48 & $€ / \mathrm{ITU}$ \\
\hline \multicolumn{4}{|c|}{ External costs } \\
\hline$c_{r p}$ & Road pollution & 0,16 & $€ / \mathrm{km}$ \\
\hline$c_{r l p}$ & Rail pollution & 0,015 & $€ / \mathrm{km}$ \\
\hline$c_{\mathrm{tp}}$ & Transhipment pollution & 0,113 & $€ / \mathrm{km}$ \\
\hline$c_{\mathrm{rn}}$ & Road noise & 0,245 & $€ / \mathrm{km}$ \\
\hline$c_{r l n}$ & Rail noise & 0,175 & $€ / \mathrm{km}$ \\
\hline$c_{r w}$ & Road global warming & 0,046 & $€ / \mathrm{km}$ \\
\hline$c_{r l w}$ & Rail global warming & 0,01 & $€ / \mathrm{ITU} / \mathrm{km}$ \\
\hline$c_{\mathrm{tw}}$ & Transhipment global warming & 0,083 & $€ /$ movement \\
\hline
\end{tabular}

not being, a function of the distance. The average values displayed in Table 1 refer to the transport of a standard ITU $\left(40^{\prime}\right.$ or $\mathrm{FEU}^{4}$ ) [21]. As for the externalities, it was decided to disregard accidents and congestion because of the unreliability or - at least - the level of uncertainty of the available data; the reference scales are not easily or accurately usable in a direct comparison.

As far as transhipment is concerned, operations within the terminals were used as a summary value for the transport unit, which inherently involves movements, operations boundary, railway manoeuvres and internal checks, as well as the average time that the truck spends inside the terminal. In this phase of the study, single cost items of the terminal activities were not investigated in detail because of the great uncertainty of the related variables.

By varying the length of the drayage, from 0 to $120 \mathrm{~km}$, different scenarios were created. The analytical approach was aimed at correlating the costs with the distances $(d)$ by separating the internal ones from the external ones.

The cost calculation for the road-only alternative was articulated as follows:

$$
C_{\text {road }}=c_{\text {road }} d+\left(c_{r_{p}}+c_{r_{n}}+c_{r_{w}}\right) d
$$

The final cost for the ferroutage called for a more complex formulation, because another variable had to be introduced, namely the location of the inland terminals $\left(d_{\text {terminal }}\right)$. The cost composition for a single component 
of a combined transport chain is visible in the following list of formulas; this underlines that the result would be a function of the progressive distance:

- pre- road haulage

$$
C_{c t_{-} r 1}=c_{h} d+\left(c_{r_{p}}+c_{r_{n}}+c_{r_{w}}\right) d
$$

- terminal 1

$$
\begin{aligned}
C_{c t_{-} t}= & c_{h} d+c_{t}+\left(c_{r_{p}}+c_{r_{n}}+c_{r_{w}}\right) d \\
& +\left(c_{t_{p}}+c_{t_{w}}\right)
\end{aligned}
$$

- rail main haulage

$$
\begin{aligned}
C_{c t \_r l}= & C_{c t \_t}+c_{r l}\left(d-d_{\text {terminal }}\right) \\
& +\left(c_{r_{l p}}+c_{r l_{n}}+c_{r l_{w}}\right)\left(d-d_{\text {terminal }}\right)
\end{aligned}
$$

- terminal 2

$$
C_{c t \_t 2}=C_{c t \_r l}+c_{t}+\left(c_{t_{p}}+c_{t_{w}}\right)
$$

- post road haulage

$$
\begin{aligned}
C_{c t_{r f}}= & C_{c t_{t 2}}+c_{h}\left(d-d_{\text {terminal } 2}\right) \\
& +\left(c_{r_{p}}+c_{r_{n}}+c_{r_{w}}\right)\left(d-d_{\text {terminal } 2}\right)
\end{aligned}
$$

The length of a train can obviously influence the final cost of train traction. In many countries in Europe and around the world, trains made up of approx. 20 freight cars, for an overall load of roughly 60 TEU's, are standard practice; in other countries, the figures rise to 35 wagons, or even more (Australia, Russia, the United States, albeit on generally flat landscapes). The lengthening of the train, which can be obtained, if required, by the composition of several shorter convoys or through distributed-power freight ones (which do not exist so far, though they are consolidated trains for passenger transport, namely for high fast and speed trains), would allow a greater production of tons per kilometre per driver, if the train were fully loaded, thus reducing the unit cost per load unit [20].

\section{Results and discussion}

The following results, derived from the method described in this paper, have always been expressed as cost-related to the transport of one standard ITU $\left(40^{\prime}\right.$ or FEU). The typical trend obtained from the scenario with a distance between terminals and origin of the shipment (the same for the destination) equivalent to $40 \mathrm{~km}$ was only chosen as an example (see Fig. 6). The function is discontinuous, due to the presence of terminal operations and the related cost items are independent of the covered kilometres. As expected, the slope of the line is more marked for road traction, mainly in relation to external costs.

The variation in the balance point between the two cost functions is shifted towards greater distances as the pre- and post-haulage increase (see Fig. 7).

The external costs make combined transport competitive, since - if only the internal costs were considered the economic advantage obtained by using the rail mode for the main distance would not be enough to offset the costs of the transhipment operations, or the higher costs for the initial and final road traction (see Fig. 8).

The share of the total cost of combined transport due to terminal processes (see Fig. 9) is lower than for the other components, but it is still quite relevant, since it is unrelated to the distance and does not come into play for the "road only" option. The efficiency of rail freight transport, and thus also of the intermodal mode, depends to a great extent on the role of the terminals. The terminal process needs a method that costs less and which is less time consuming [7].

Therefore, incorporating the results obtained from several scenarios, from the qualitative point of view, it is possible to state that rail-road transport is competitive, compared with the full-road alternative, considering all the costs, up to distances to link the initial or final shipment points and the destinations with the chosen (usually the closest) terminals of about $100 \mathrm{~km}$ or less (see Fig. 10). If the comparison takes into consideration the internal costs (see Fig. 11), combined transport, on the basis of the assumptions and inputs of this paper, would not appear to be competitive enough versus the unimodal road solution. In conclusion, choosing the rail mode for the main portion of the pathway involves substantial advantages, but mainly in terms of environmental efficiency, such as reduced pollution, which - as previously stated - is computed as an external cost (see Fig. 12).

At the end of the analysis, the previous formulas were implemented by changing the distance between 


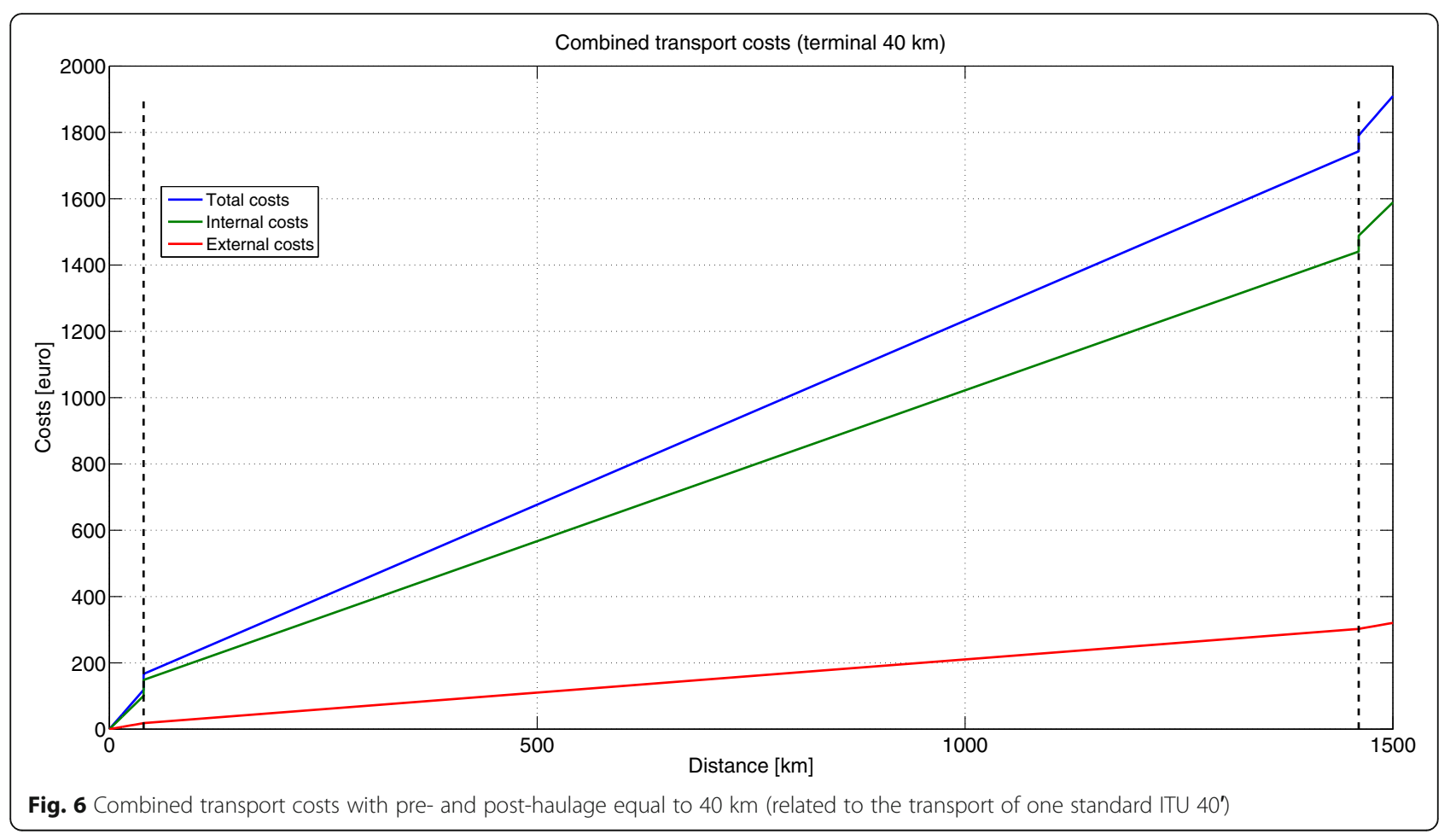

the origin and the destination, in particular for transport over lengths of 1000, 1500, 2000 and $2500 \mathrm{~km}$ (see Figs. 13 and 14). It is interesting to note the shift towards the right of the equilibrium point between the cost of the unimodal road transport and that of rail-road combined transport. This means that, over long distances, combined transport can be economically competitive, even when the drayage covers greater distances; this aspect has not yet been sufficiently highlighted in the relevant literature.

The location of terminals was kept constant, and the variation of the total transport costs for rail-road
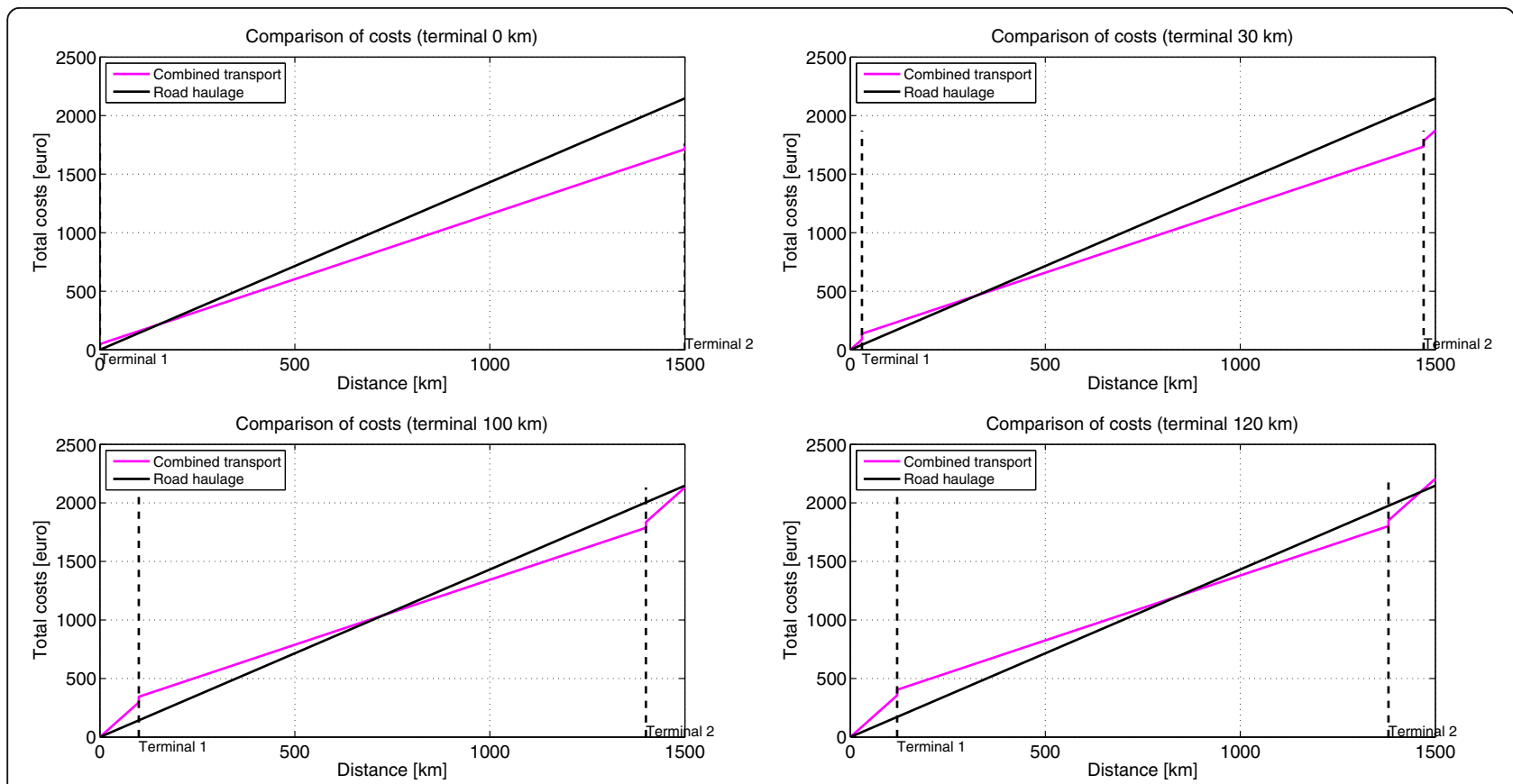

Fig. 7 Comparison of the total costs for freight transport as a function of the terminal location (related to the transport of one standard ITU 40') 

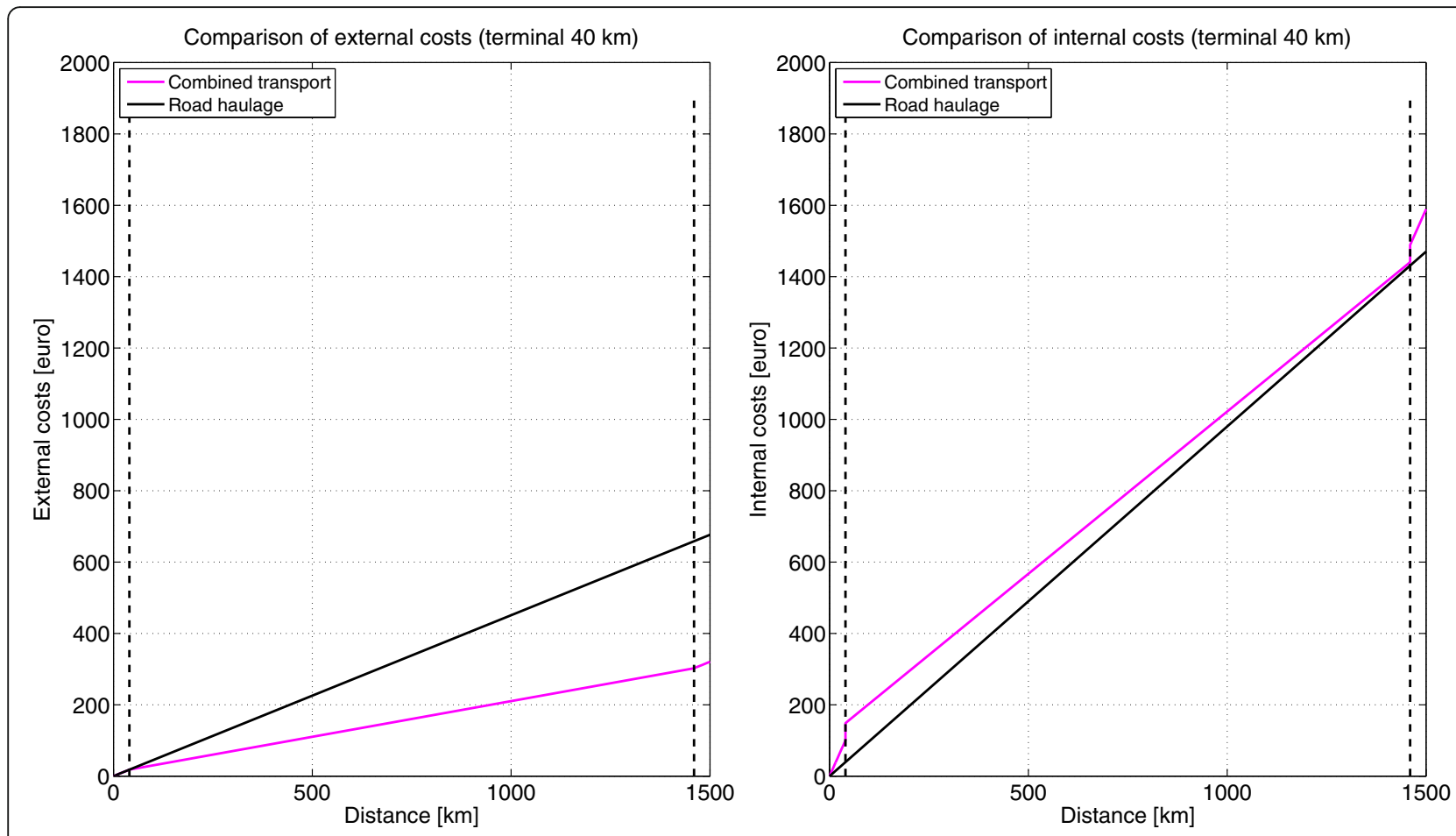

Fig. 8 Comparison of the external and internal costs for the two alternatives (terminal location: $40 \mathrm{~km}$ ) (related to the transport of one standard ITU 40')

combined transport and full-road was assessed as a function of the door-to-door distance (some cases in Figs. 14 and 15).

The total costs increase with the distance, due to the chosen method. Rail-road combined transport can be

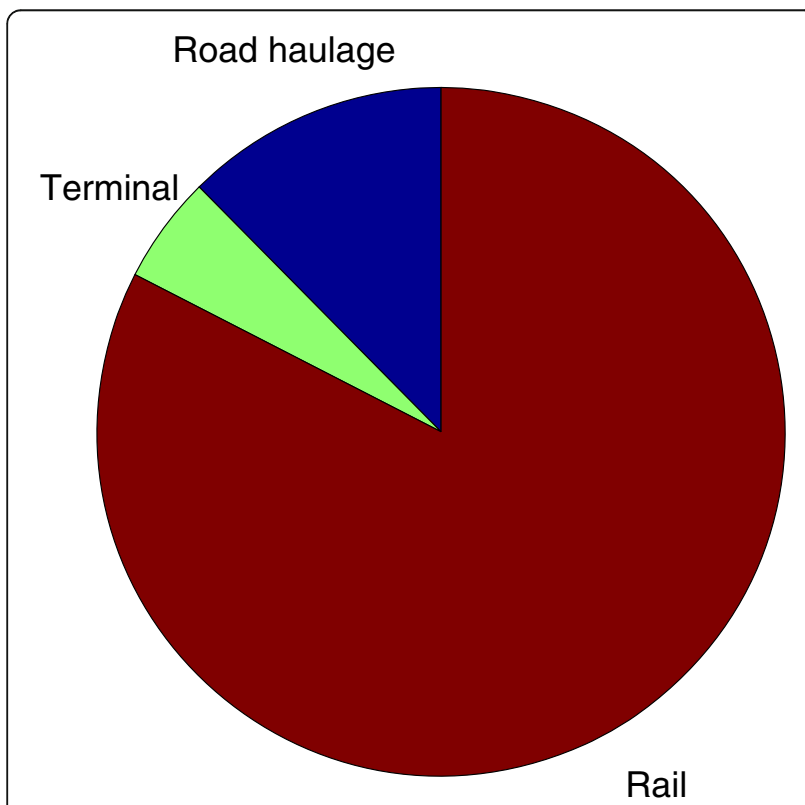

Fig. 9 Influence of each cost item on the final combined transport price cost-effective vs. the full-road mode, when a drayage of $40 \mathrm{~km}$ was assumed and when the distance between the origin and destination was approx. $750 \mathrm{~km}$, i.e. a comparable value with those that have already been mentioned in the scientific literature; such a value would increase if the terminals were located far from the origin and destination points.

\section{Technical considerations}

\subsection{Shuttle freight trains: Seaport and dry port connections}

A shuttle freight train service is typically characterised by a scheduled and fixed composition of convoys as well as fixed path allocations. The usually covered distances are short, compared to the traditional rail ones, and as has emerged from $\$ 3$. However, this alternative is being adopted successfully, especially for port (or seaport) and back-port (or dry port ${ }^{5}$ ) connections. In fact, the phenomenon of increasing ship capacity can lead to a port infrastructure crisis, and the role of back-ports (terminals or logistic platforms near the ports) is becoming significant. It is now more important than ever to act on the port connections with the hinterland, in part to enhance the ports themselves. These routes are often covered by road transport, because ports do not always have good and efficient railway connections. In terms of productivity and efficiency, a shuttle service can be a convenient choice. Trains with a fixed composition lead to 


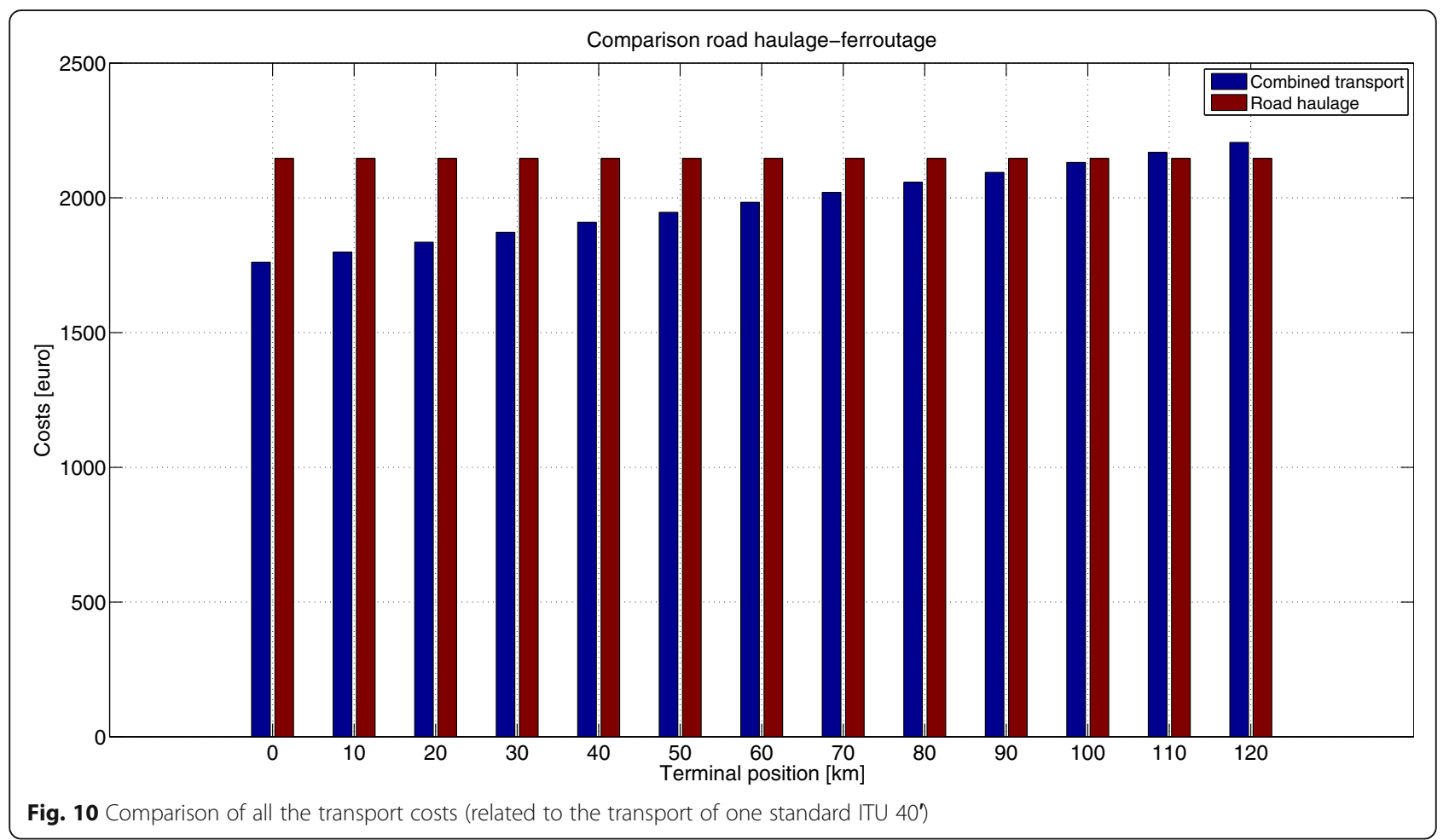

lower costs and less time for terminal operations. It is important to consider the digital tachograph obligation, with the associated rest times for drivers, as one of the main limitations of road transport. In short, according to the EU rules on driving hours, a truck driver must not drive more than:

- $9 \mathrm{~h}$ a day - this can be extended to $10 \mathrm{~h}$ twice a week;

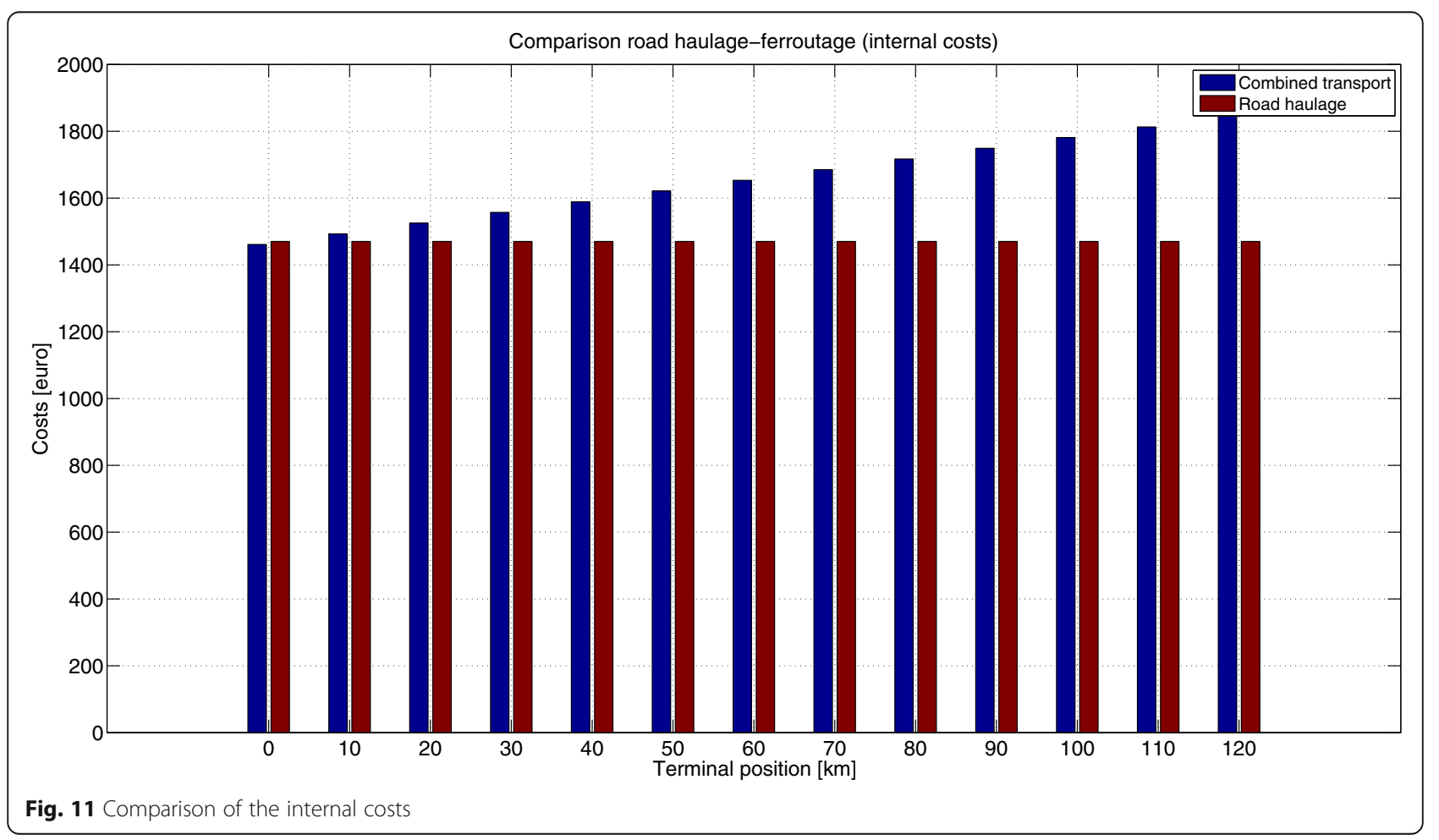




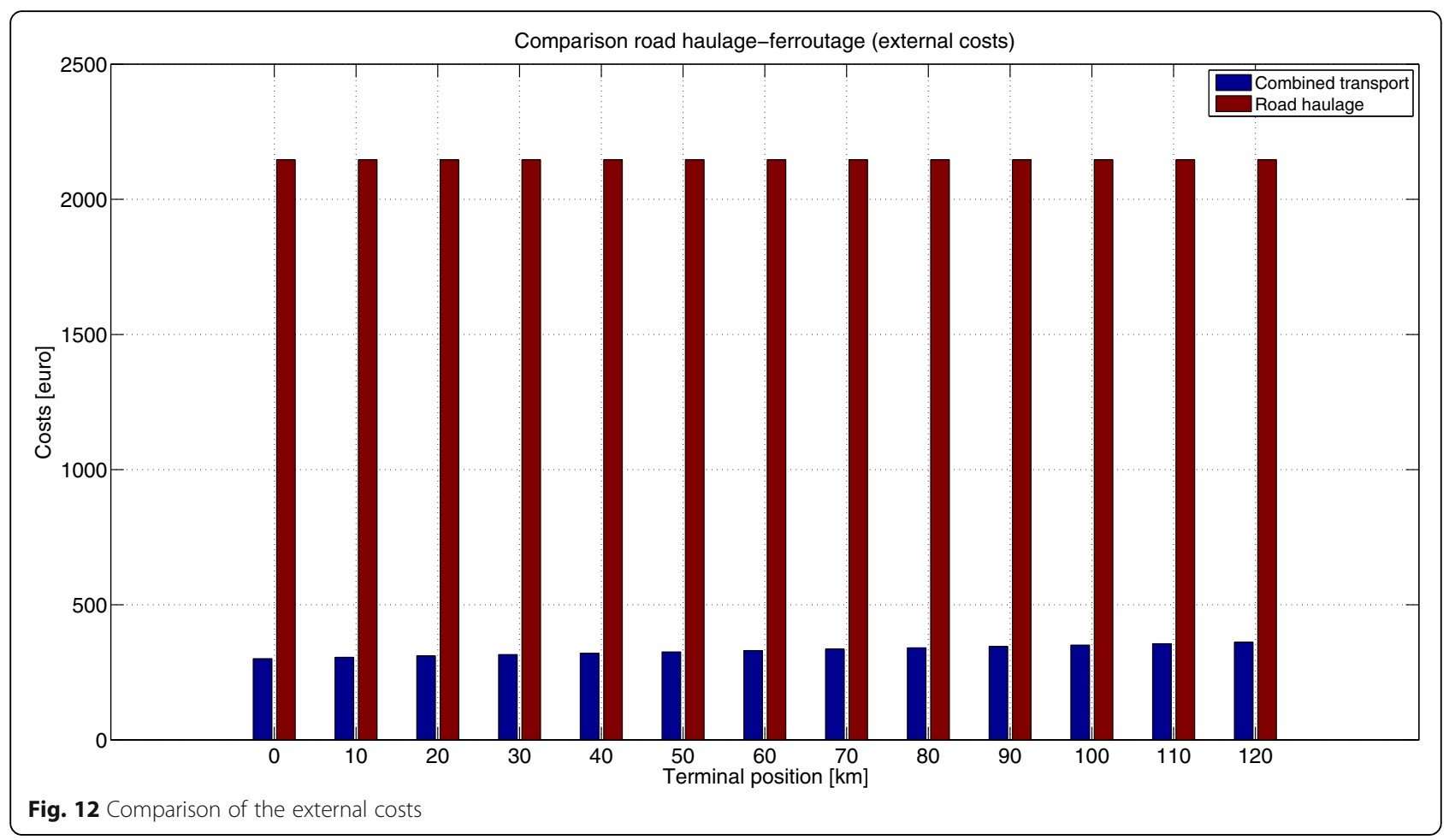

- 56 h a week;

- $90 \mathrm{~h}$ in any 2 consecutive weeks.

Genova-Rivalta Scrivia, which is an important location in the TEN-T Corridor framework, is an example of a seaport and dry port connection, though many other exist or may develop (Port Savona Vado-Turin, Port of NaplesNola, etc.). Crainic et al. [24] used a similar regional case to validate their service network design model for the planning of the optimal routes and schedules for a fleet

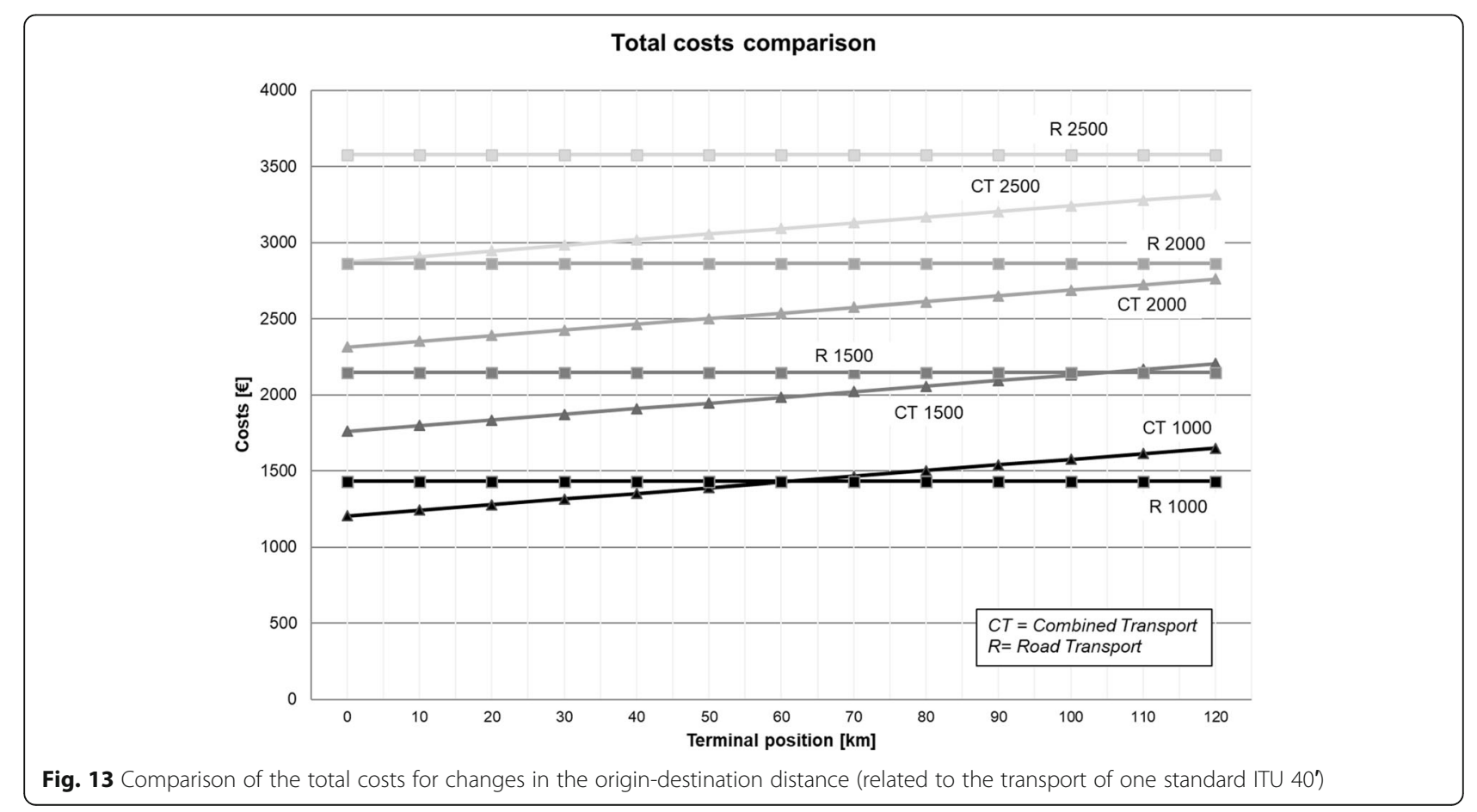




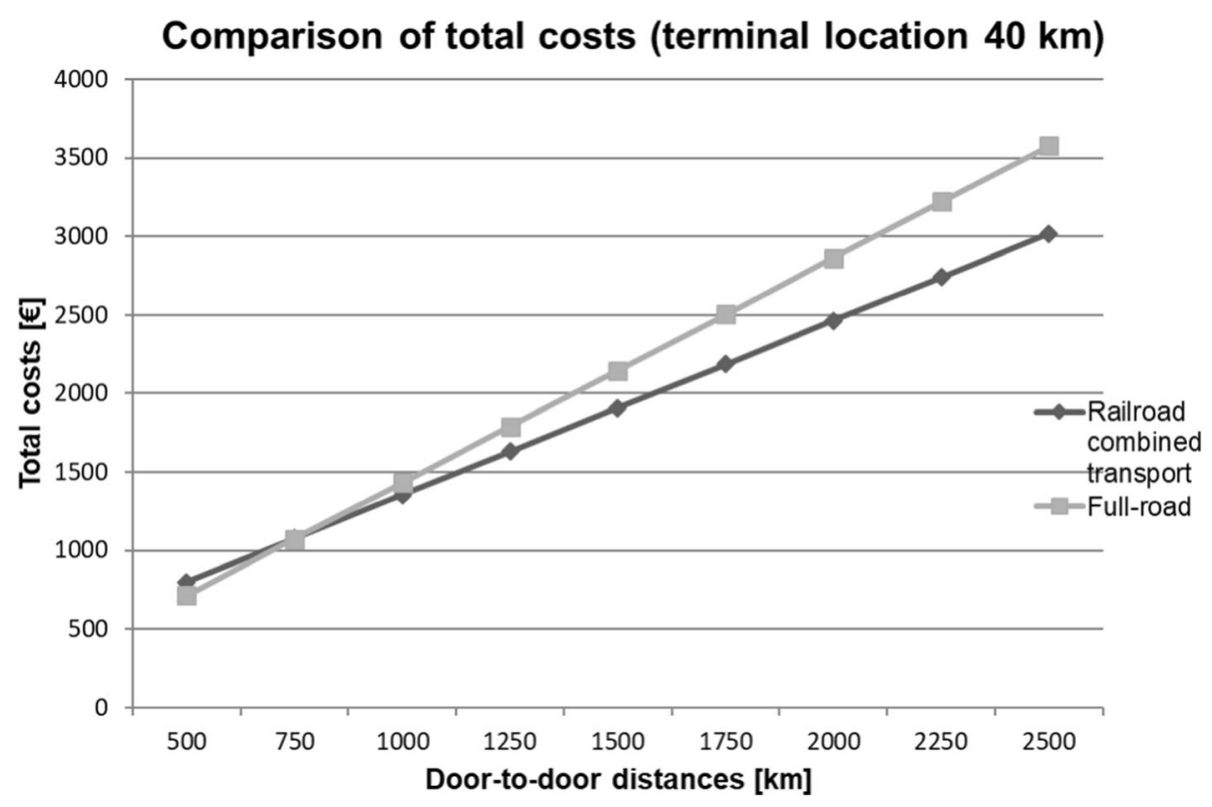

Fig. 14 Comparison of the total costs as a function of the distance between the origin and destination (terminal location: $40 \mathrm{~km}$; related to the transport of one standard ITU 40')

providing transportation services between the terminals of a dry-port-based intermodal system.

The distance covered by trucks is approx. $80 \mathrm{~km}$, whereas the length of the railway is approx. $65 \mathrm{~km}$. Hypothetically, the speeds could be chosen as $100 \mathrm{~km} / \mathrm{h}$ for trains and $60 \mathrm{~km} / \mathrm{h}$ for trucks. The largest cargo ship that can be accommodated in the Genova Port has a capacity of $14,000 \mathrm{TEU}$, thus if $40^{\prime}$ containers were considered, the total amount of ITUs would be 7000. If the destination of $60 \%$ of these containers was the Interporto of Rivalta Scrivia, it is possible to compare, through a simplified calculation, train shuttle (approx. 20 ITUs per train) and truck fleet services. It was assumed, for the cycle time calculation, that the terminal operations needed $1 \mathrm{~h}$ per truck and $2.5 \mathrm{~h}$ per train. The cycle time was calculated as almost $5 \mathrm{~h}$, in the case of a truck, and $6.2 \mathrm{~h}$ for a train. Therefore, one truck and one train can carry out two roundtrips according to the driving constrains and assuming a certain degree of occupation of the route (see Fig. 16). One truck can obviously carry just 1 ITU, while a train can carry at least 20 ITUs. Thus, without considering what happens on the return journey, trucks can carry out 2 ITUs per day, while a train shuttle can perform 40 ITUs.

It is possible to hypothesise 3 shuttle trains per day, but neglecting the terminal capacity and the availability of the train paths, for a total of 120 ITUs to the Interporto per day. At least 35 days of train shuttle service would be required to deliver 4200 ITUs (see Fig. 17).

In order to ensure deliveries in the same time, the truck fleet would need to be composed of 84 drivers operating five days per week. It is easy to see that the second solution is less convenient, in terms of economics, efficiency and environment.

The convenience of the rail mode can also emerge for short distances, but in the case of specific services, such as a shuttle train, with scheduled and fixed compositions and large quantities of goods with the same path, which require lower times and costs for terminal operations.

\subsection{Alternative solutions for road transport: Hybrid and electric heavy-duty vehicles}

The role of pre- and post-haulage covered by road in combined transport is relevant, as pointed out in the previous sections, both in terms of internal and external costs. Ye et al. [25] analysed the potential of longer and heavier vehicles, related, for instance, to pre- and post-haulage. They showed that these types of trucks contribute to improving intermodal transport efficiency, thanks to internal and external cost formulas, in which volume variables were considered. Other solutions to improve the efficiency of road drayage could be in terms of power supply. A number of manufacturers are currently proposing new solutions for the power supply of trucks, such as electric vehicles for lower classes of weight (up to roughly $5-7.5$ tons), hybrid vehicles and CNG or LNG engines for higher weights. These alternatives, in particular the hybrid or electric ones, are usually compatible with the distances covered during pre- and post-haulage, considering the location of charging stations in the terminals. The positive effects of replacing traditional engines are 

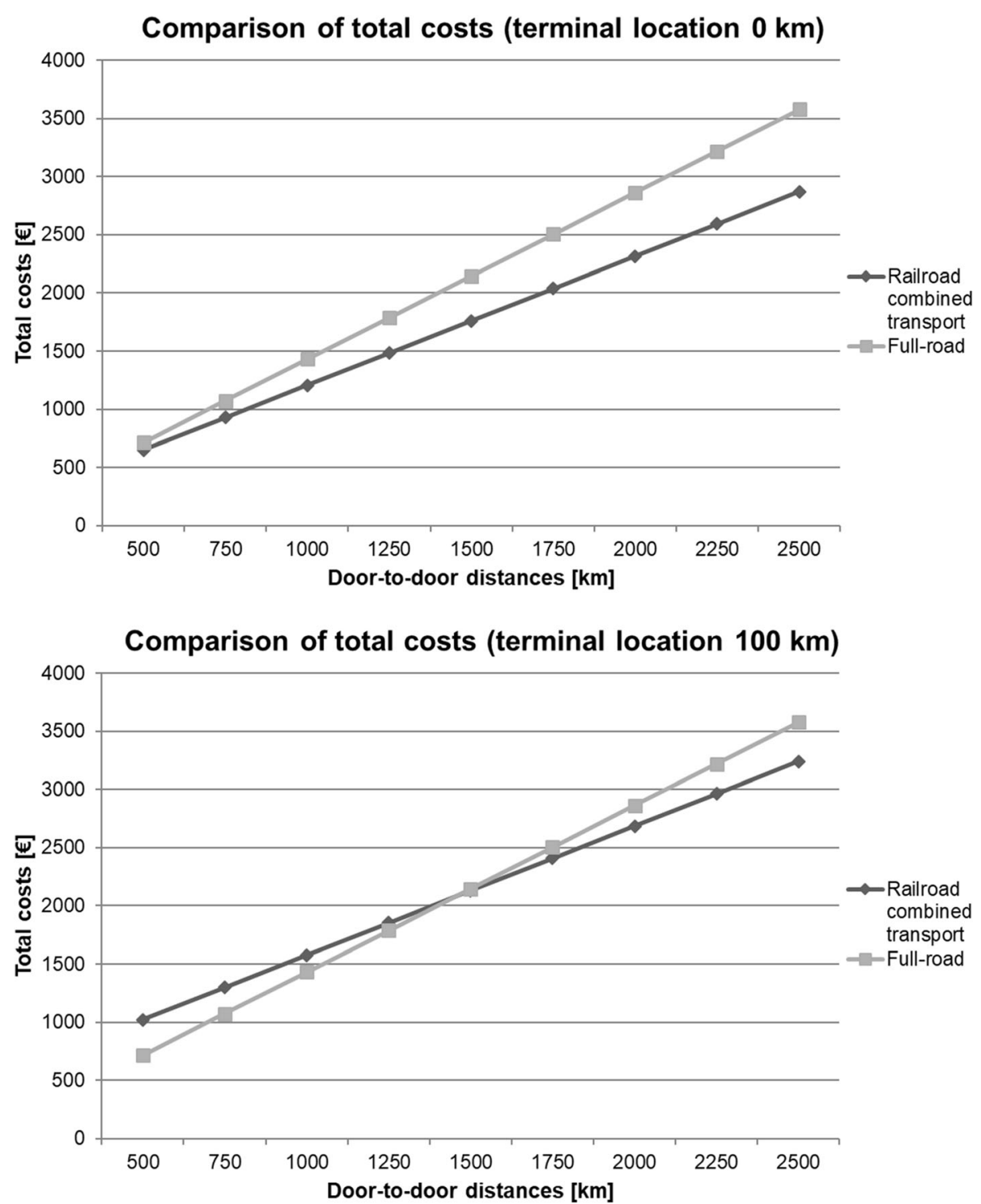

Fig. 15 Comparison of the total costs as a function of the distance between the origin and destination (drayage length: $0 \mathrm{~km}$ and $100 \mathrm{~km}$; related to the transport of one standard ITU 40')

mainly reflected on the external costs, due to the reduction in emissions, and on the internal costs, in terms of consumption. Furthermore, the final section of rail-road combined transport usually takes place on urban routes, which are subject to environmental restrictions in many cities.

Moultak et al. [26] compared three technologies for zero-emission heavy-duty freight vehicles: electric plug-in, electric catenary or in-road charging and hydrogen fuel cell. They found that electric and hydrogen fuel cell vehicles would cost $25 \%-30 \%$ and $5 \%-30 \%$, respectively, less than diesel vehicles. Another outcome of their work, which confirms what is proposed in this paper, is: the hydrogen fuel cell might be a key element for long distances, while plug-in electric vans may be useful, in economic and environmental terms, to cover shorter distances (for a range of approx. 100-200 km).

Figure 18 shows the hypothetical contribution of the introduction of alternative fuels for pre- and post-haulage. This improvement is taken into account with a reduction of $20 \%$ for road costs, which is a realistic percentage, according to recent data in the literature. In comparison to Fig. 8, the break-even point between the two alternatives is now visible and at around $700 \mathrm{~km}$ for internal costs.

\section{Conclusions}

After defining the linear cost functions for rail-road combined transport, 13 scenarios have been created by changing both the initial and final length of drayage, 


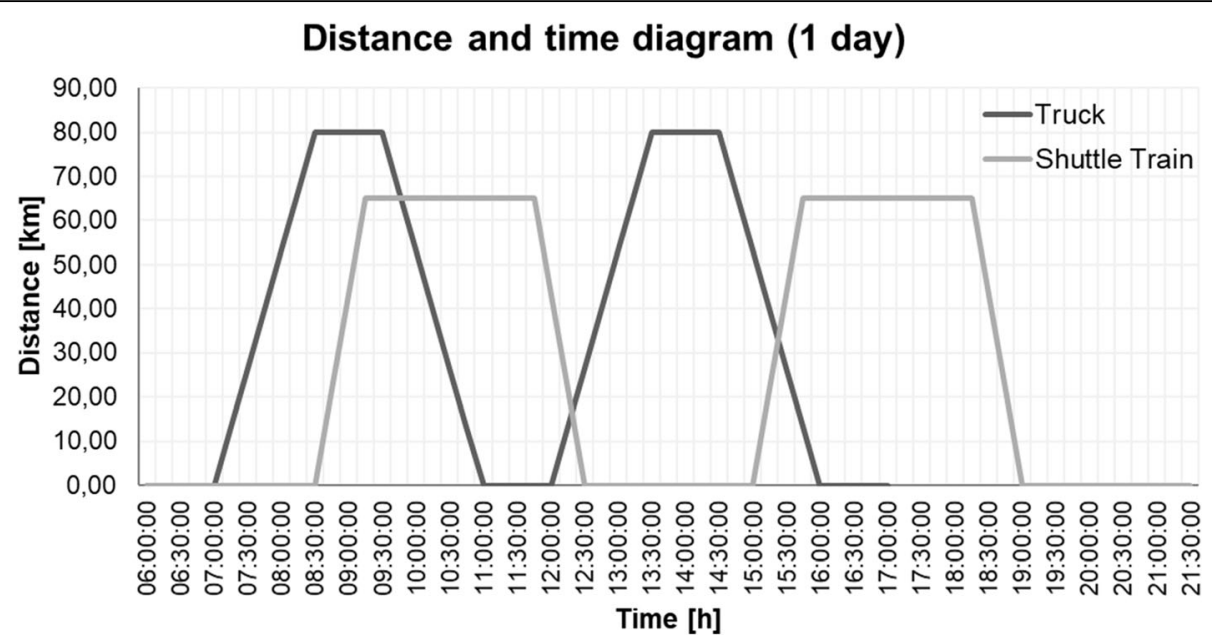

Fig. 16 Diagram of an example of a truck service and a shuttle train service in a day

from $0 \mathrm{~km}$ to $120 \mathrm{~km}$, then separating the internal from the external costs. Subsequently, other scenarios have been generated by varying both the pre- and post- haulage and the distance between the origins and destinations.

The starting point was the reproduction of a typical trend, which is often only given qualitatively in the literature, of the costs versus distance of combined transport, using the discussed method, and some rather realistic values have been indicated, despite their high uncertainty.
Furthermore, the paper confirms, and contributes with further details obtained from different sources, what Santos et al. [16] obtained in their study: the advantage on the external costs is lower when the drayage is of an excessively high proportion, since negative aspects of road transport play a greater role. This problem can be overcome by using, for instance, alternative fuels or energy carriers for trucks.

In conclusion, the results reflect what might be expected: the location of inland terminals influences the preand post-haulage by road and has a heavy impact on the

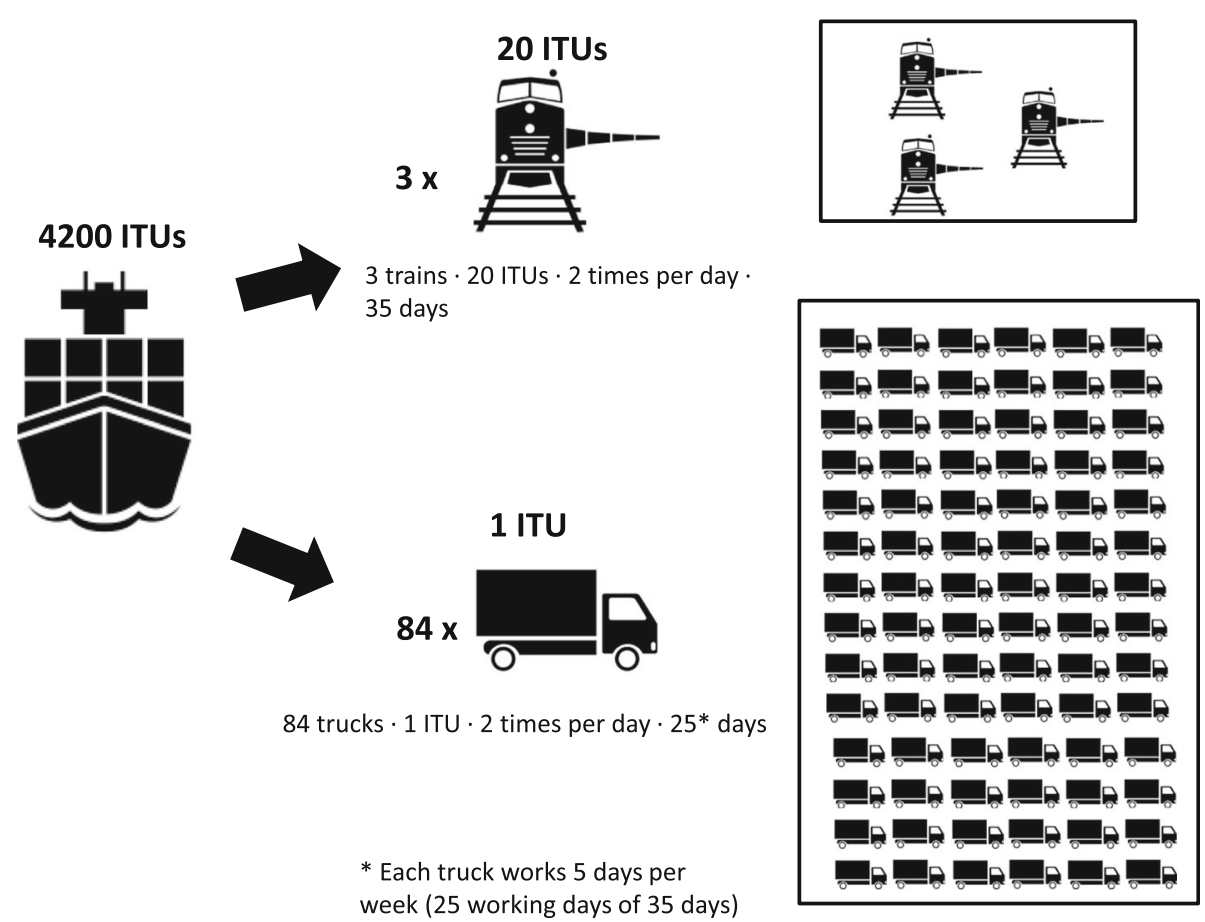

Fig. 17 Comparison of a shuttle train service and a truck fleet service carrying containers from a port to a back port in 35 days 

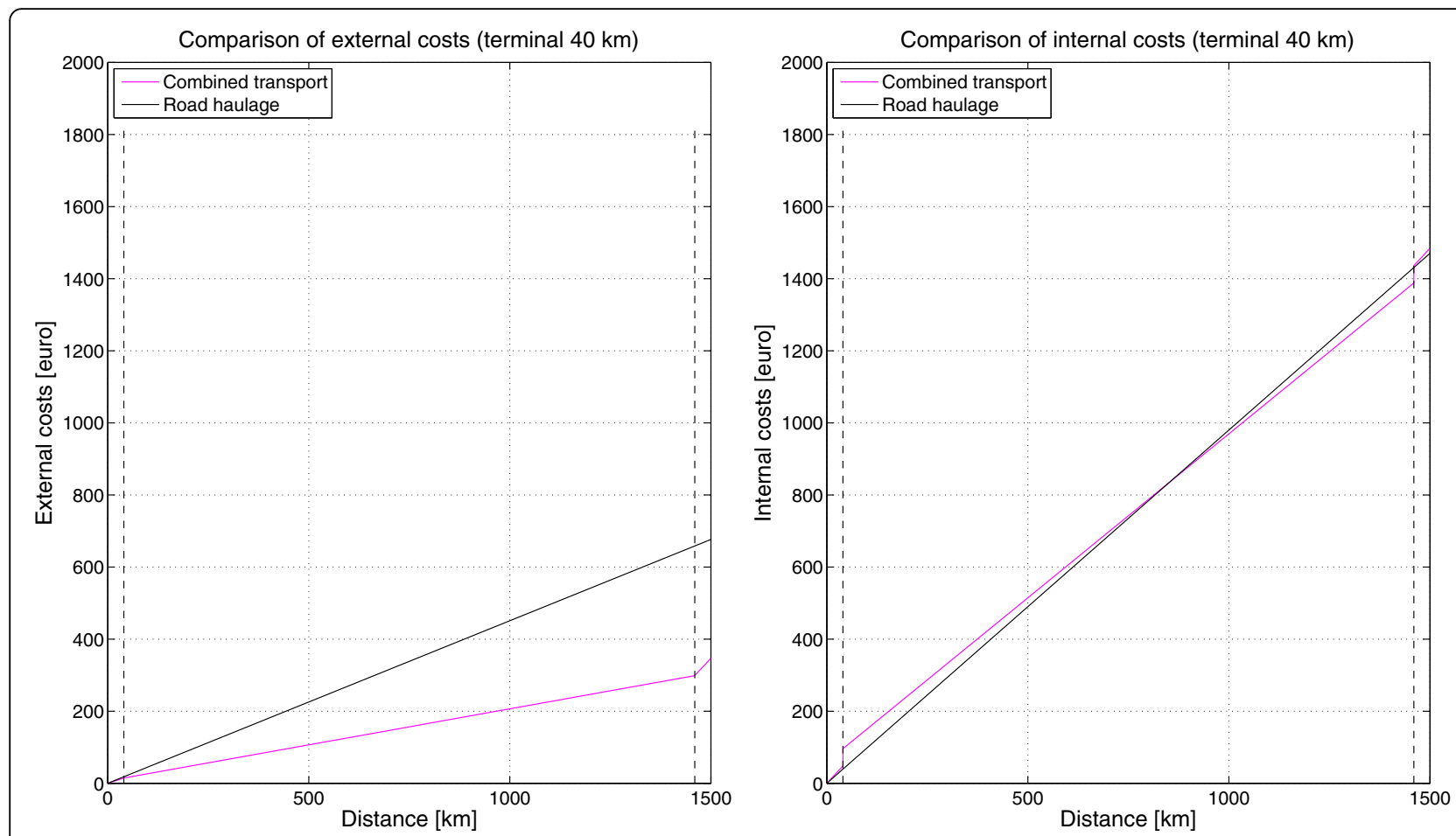

Fig. 18 Comparison of the external and internal costs for the two alternatives using an electric solution for drayage (terminal location: $40 \mathrm{~km}$ ) (related to the transport of one standard ITU 40')

final price. We here confirm that rail-road transport may be competitive if the external costs are internalised, as pointed out in the work by Mostert and Limbourg [17], and if the total distances are sufficient to exploit the advantages of rail transport, with a limited resort to drayage. In order to underline this latter point, the initial length assumed from the origin to the destination has been varied to ascertain whether combined transport is efficient over long distances. Rail-road combined transport over longer door-to-door distances (approx. $2000 \mathrm{~km}$ ) may be cost-effective, even for a high drayage length, an aspect that tends to have been overlooked in the literature.

This paper shows that full-road transport is cost effective for a medium pre- and post-haulage of $40 \mathrm{~km}$ and for lower door-to-door distances than approximately $800 \mathrm{~km}$. These results are in agreement with those presented by Janic [19] and by Mostert and Limbourg [17], where, however, the length of drayage was not always specified, even though the obtained trend of costs versus door-to-door distance is different, due to the adopted approach and assumptions.

In the case of short distances, the cost of the terminal operations to shift from one mode of transport to another one limits the competitiveness of intermodal transport. When the distances increase, the economic advantage of the alternative mode is prevalent, i.e. sufficient to cover the additional amount due to transhipment. A significant advantage in terms of environmental impact and pollution would be achieved [14]. Therefore, if the railway haulage is too short, the economic benefit of the intermodal alternative is overpowered by the terminal costs and the pre/post road haulage [27].

The paper has also shown that these considerations may not be suitable in some cases, such as in the case of a short distance (seaport and dry port connection) covered by a shuttle train: scheduled and fixed composition, large quantities of goods with the same path. In fact, this type of service requires lower times and costs for terminal operations and the reduction or elimination of pre- haulage, which have less influence on rail competitiveness. The number of trucks necessary to move the same amount of goods at the same time, compared to the railway mode, can be very high and can result in effects in terms of congestion, pollution and infrastructure maintenance. The topicality of the theme, at a national Italian level, is also highlighted by the current "Piano Strategico Nazionale della Portualità e della Logistica" [28], where the importance of the development of dry ports is highlighted.

Finally, some considerations are presented about alternative solutions for road transport, in particular electric and hybrid heavy-duty vehicles. The length of drayage covered by road could be compatible with these power supply alternatives, and their qualities 
could improve the competitiveness of the rail-road combined transport system.

This paper intends to be the kick-off of a larger study whose aim will be the assessment of the competitiveness of rail-road transport. This will be attained through optimizing the efficiency of the terminal operations, in both economic and energy terms, by implementing ITS (Intelligent Transport System) technologies. Future works will cover the creation of new exploratory scenarios, in which the initial assumptions will be varied, for example, by eliminating the symmetry of the interchange terminal positions, the cost functions will be examined in detail, and new variables, such as road congestion externalities, will be introduced.

\section{Endnotes}

${ }^{1}$ Drayage is the transport of goods over a short distance via ground freight, or the charge of such transport. In this paper we consider the former definition.

${ }^{2}$ In this paper, we have considered a rail-road combined transport chain for door-to-door transport, while goods consolidation and deconsolidation operations, that is, when goods are inside the transport unit, have been excluded.

${ }^{3}$ Intermodal Transport Unit: a rigid and crushproof structure, generally unified in size and in some of its components, which is suitable for the containment and protection of goods and for mechanical transfer between different modes of transport [3]. The most common solutions are containers, which were created in particular for maritime transport, as well as swap bodies and semitrailers, which are suitable for rail-road transport.

${ }^{4}$ Forty-foot equivalent unit

${ }^{5}$ Dry ports are defined as inland freight terminals that are connected directly to one or more seaports with high-capacity transport means, where customers can drop off and pick up their standardised units as if they were at a seaport [24].

\section{Publisher's Note}

Springer Nature remains neutral with regard to jurisdictional claims in published maps and institutional affiliations.

Received: 5 February 2018 Accepted: 18 September 2018

Published online: 28 September 2018

\section{References}

1. European Commission (2011) WHITE PAPER: roadmap to a single European transport area - towards a competitive and resource efficient transport system. Bruxelles

2. Economic Commission for Europe (UN/ECE) (2001) Terminology on combined transport. New York and Geneva

3. Dalla Chiara B (2015) Sistemi di trasporto intermodali: progettazione ed esercizio, 2nd edn EGAF

4. Commission of the European communities (2008) Strategy for the internalisation of external costs. Bruxelles

5. Demir E, Huang Y, Scholts S, Van WT (2015) A selected review on the negative externalities of the freight transportation: modeling and pricing. Transp Res Part E 77:95-114. https://doi.org/10.1016/j.tre.2015.02.020
6. Mathisen TA, Hanssen T-ES (2014) The academic literature on intermodal freight transport. Transp Res Procedia 3:611-620. https://doi.org/10.1016/j. trpro.2014.10.040

7. Islam DMZ, Ricci S, Nelldal BL (2016) How to make modal shift from road to rail possible in the European transport market, as aspired to in the EU transport White paper 2011. Eur Transp Res Rev 8. pp 8-18 https://doi.org/ 10.1007/s12544-016-0204-x

8. Skočibušić MB, Stupalo V, Sanja K (2011) Technological and economic aspects of intermodal transport. Commun Comput Inf Sci 239:403-408. https://doi.org/10.1007/978-3-642-24660-9_46

9. Frémont A, Franc P (2010) Hinterland transportation in Europe: combined transport versus road transport. J Transp Geogr 18:548-556. https://doi.org/ 10.1016/j.jtrangeo.2010.03.009

10. Hanssen T-ES, Mathisen TA, Jørgensen F (2012) Generalized transport costs in intermodal freight transport. Procedia - Soc Behav Sci 54:189-200. https:// doi.org/10.1016/j.sbspro.2012.09.738

11. Kim NS, Van Wee B (2011) The relative importance of factors that influence the break-even distance of intermodal freight transport systems. J Transp Geogr 19:859-875. https://doi.org/10.1016/j.jtrangeo.2010.11.001

12. Ballis A (2004) Introducing Level of Service Standards for Intermodal Freight Terminals. In: TRB. Transportation Research Record. Journal of the Transportation Research Board, Washington, pp 79-88

13. Behrends S, Flodén J (2012) The effect of transhipment costs on the performance of intermodal line-trains. Logist Res 4:127-136. https://doi.org/ 10.1007/s12159-012-0066-0

14. Carreira JS, Santos BF, Limbourg S (2012) Inland intermodal freight transport modelling. In: European Transport Conference 2012. ETC Proceedings, Glasgow

15. Limbourg S, Jourquin B (2008) Optimal rail-road container terminal locations on the European network. Transp Res Part E 45:551-563. https://doi.org/10. 1016/j.tre.2008.12.003

16. Santos BF, Limbourg S, Carreira JS (2015) The impact of transport policies on railroad intermodal freight competitiveness - the case of Belgium. Transp Res Part D Transp Environ 34:230-244. https://doi.org/10.1016/j.trd. 2014.10.015

17. Mostert M, Limbourg S (2016) External costs as competitiveness factors for freight transport - a state of the art. Transp Rev 36:692-712. https://doi. org/10.1080/01441647.2015.1137653

18. Kos S, Vukić L, Brčić D (2017) Comparison of external costs in multimodal container transport chain. PROMET - Traffic\&Transportation 29:243. https:// doi.org/10.7307/ptt.v29i2.2183

19. Janic M (2007) Modelling the full costs of an intermodal and road freight transport network. Transp Res Part D Transp Environ 12:33-44. https://doi. org/10.1016/j.trd.2006.10.004

20. Dalla Chiara B, Pellicelli M (2011) On the cost of road-rail combined transport. Ing Ferrov 11:951-965

21. Black I, Seaton R, Ricci A, Enei R (2003) RECORDIT Final Report : Actions to Promote Intermodal Transport

22. Association of American Railroads (2017) The Environmental Benefits of Moving Freight by Rail

23. Horn B, Nemoto T (2005) Intermodal Logistics Policies in the EU, the U. S. and Japan

24. Crainic TG, Dell'Olmo P, Ricciardi N, Sgalambro A (2015) Modeling dry-portbased freight distribution planning. Transp Res Part C Emerg Technol 55: 518-534. https://doi.org/10.1016/j.trc.2015.03.026

25. Ye Y, Shen J, Bergqvist R (2014) High-capacity transport associated with preand post-haulage in intermodal road-rail transport. J Transp Technol 4:289301. https://doi.org/10.4236/jtts.2014.43026

26. Moultak M, Lutsey N, Hall D (2017) Transitioning to zero-emission heavyduty freight vehicles. Washington, D.C.

27. Bureau of Infrastructure Transport and Regional Economics (BITRE) (2016) Why short-haul intermodal rail services succeed, research report 139. Canberra ACT

28. Ministero delle Infrastrutture e dei Trasporti (2015) Piano strategico nazionale della portualità e della logistica 